\title{
Colonic plasmacytomas: a rare complication of plasma cell leukemia
}
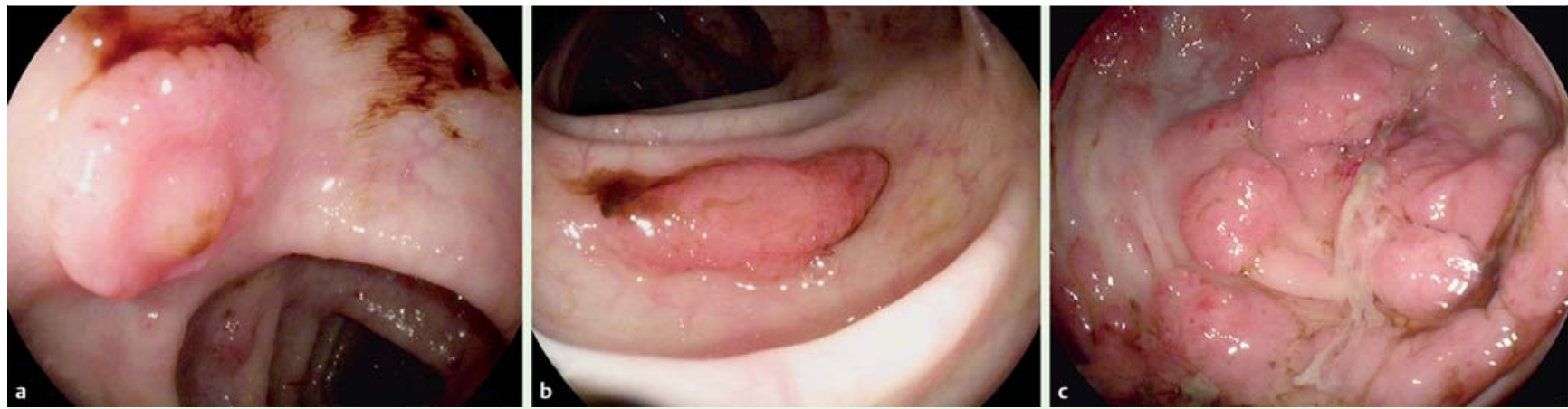

Fig. 1 A 53-year-old man diagnosed with plasma cell leukemia (PCL) was started on carfilzomib and dexamethasone but 3 days into treatment, he developed profound anemia from hematochezia requiring multiple transfusions. Colonoscopy revealed numerous polypoid growths from the transverse colon to the cecum. a A wide-based discoid polypoid lesion in the transverse colon. b Solitary polypoid lesion in the transverse colon. $\mathbf{c}$ Clusters of polyps in the cecum.

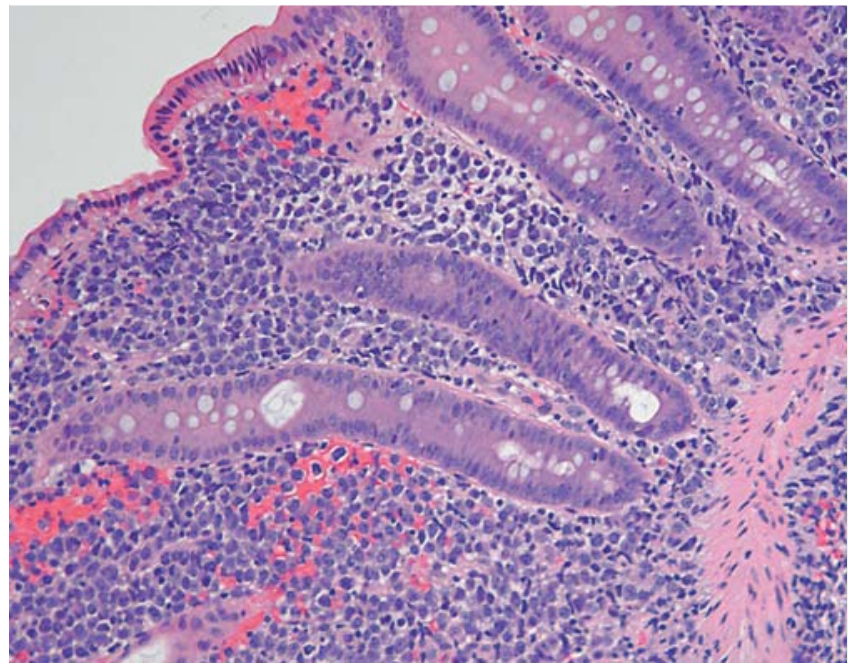

Fig. 2 Hematoxylin and eosin stain of a representative polyp demonstrating colonic mucosal infiltration by neoplastic plasma cells.

A 53-year-old man presented with fatigue, syncope, and splenic rupture. Diagnostic evaluation revealed hypercalcemia with leukocytosis $\left(23.2 \times 10^{3}\right.$ cells $\left./ \mu \mathrm{L}\right)$. Peripheral smear showed $39 \%$ lymphocytes with clonal plasmacytosis. These findings, in addition to a negative skeletal survey, suggested a diagnosis of plasma cell leukemia $(\mathrm{PCL})$. The patient was started on carfilzomib and dexamethasone after relapse following an initial regimen of cyclophosphamide, bortezomib, and dexamethasone. Then, 3 days into treatment, he developed profound anemia from hematochezia requiring multiple transfusions. Dexamethasone was stopped and esophagogastroduodenoscopy showed extensive duodenal mucositis but no active bleeding. Subsequent colonoscopy revealed numer- ous polypoid growths from the transverse colon to the cecum. These appeared both as solitary lesions and in clusters. Some were discoid, $>2 \mathrm{~cm}$ in diameter, and highly friable ( $\bullet$ Fig. 1 ).

Histology of a representative polyp revealed sheets of cells with high nuclear to cytoplasmic ratios, prominent nucleoli, and mitotic figures infiltrating the colonic mucosa ( $\bullet$ Fig. 2). These cells were positive for CD138 ( $\bullet$ Fig.3a), negative for CD20 and CD5, and were lambda light chain restricted ( $\mathbf{F i g . 3} \mathbf{b}$ ). This was consistent with colonic mucosal infiltration by a plasma cell neoplasm originally identified in peripheral blood.

Plasma cell dyscrasias include multiple myeloma, solitary plasmacytoma, and PCL, among others. Solitary plasmacyto- ma is relatively rare. Extramedullary solitary plasmacytoma typically develops in the upper respiratory tract but can rarely appear in the gastrointestinal tract [1]. PCL can be a primary leukemic process or secondary to multiple myeloma leukemic transformation. There are few cases of gastrointestinal plasmacytomas in the literature, but these either resulted from multiple myeloma or developed without any prior systemic plasma cell neoplastic disease [2-4]. To the best of our knowledge, this patient represents the first reported case of multiple colonic polyps from primary PCL infiltrating the gastrointestinal tract. As PCL is an extremely aggressive malignancy, its gastrointestinal invasion may be underreported since not all patients develop hematochezia requiring colonoscopy.

Endoscopy_UCTN_Code_CCL_1AD_2AJ

Competing interests: None

Calvin T. Hang ${ }^{1}$, Ryan B. Perumpail ${ }^{2}$, Robert J. Huang ${ }^{2}$, Sebastian FernandezPol $^{3}$, Nielsen Q. Fernandez-Becker ${ }^{2}$

${ }^{1}$ Department of Medicine, University of California, San Diego, La Jolla, California, United States

2 Department of Medicine, Stanford University, Stanford, California, United States ${ }^{3}$ Department of Pathology, Stanford University, Stanford, California, United States 


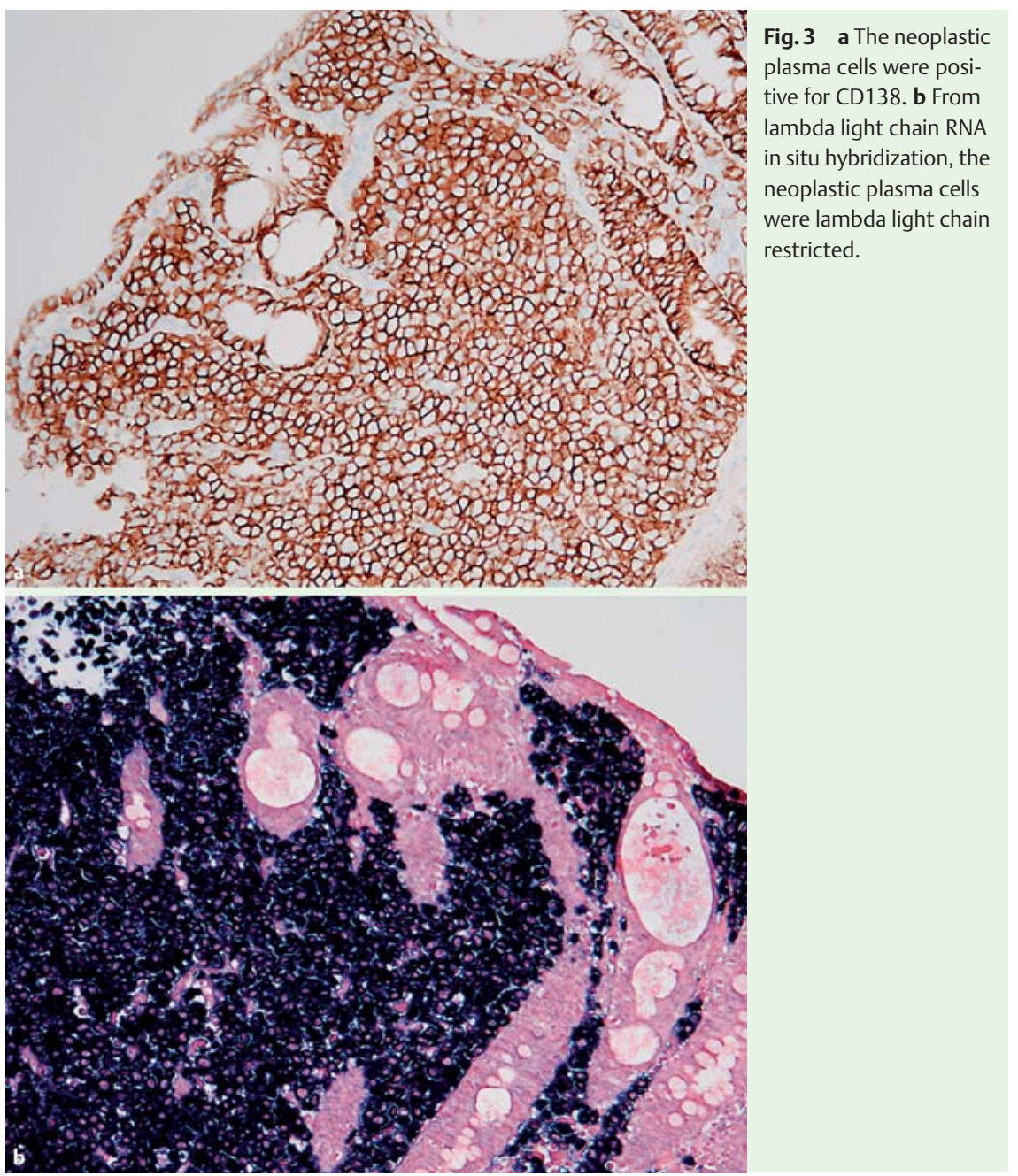

\section{References}

1 Alexiou C, Kau RJ, Dietzfelbinger $H$ et al. Extramedullary plasmacytoma: tumor occurrence and therapeutic concepts. Cancer 1999; 85: 2305-2314

2 Kodani T, Osada T, Terai $T$ et al. Successful endoscopic mucosal resection of a solitary extramedullary plasmacytoma in the sigmoid colon. Endoscopy 2011; 43 (Suppl. 02): E298-299

3 Pacheco DC, de Solorzano MM, Lazaro EQ et al. Extramedullary plasmacytoma of the colon: a rare cause of gastrointestinal bleeding. Endoscopy 2009; 41 (Suppl. 02): E306-307

4 Doki T, Takeuchi O, Kaiho $T$ et al. Primary isolated extramedullary plasmacytoma of the colon. Int J Colorectal Dis 2008; 23: $719-720$

\section{Bibliography}

DOI http://dx.doi.org/

10.1055/s-0034-1390722

Endoscopy 2015; 47: E77-E78

(c) Georg Thieme Verlag KG

Stuttgart · New York

ISSN 0013-726X

\section{Corresponding author}

Nielsen Q. Fernandez-Becker, MD, PhD

Division of Gastroenterology and Hepatology

Stanford University School of Medicine

300 Pasteur Drive

Stanford, California 94305

United States

Fax: +1-650-498-6323

Nfernan1@stanford.edu 